BMJ Open Sport \& Exercise Medicine

\title{
Mental health screening: severity and cut-off point sensitivity of the Athlete Psychological Strain Questionnaire in male and female elite athletes
}

Simon Rice (D) ,,2 Lisa Olive, ${ }^{1,3}$ Vincent Gouttebarge (1) , 4,5,6 Alexandra G Parker, ${ }^{2,7}$ Patrick Clifton, ${ }^{8}$ Peter Harcourt, ${ }^{8}$ Michael Llyod, ${ }^{9}$ Alex Kountouris, ${ }^{9}$ Ben Smith, ${ }^{10}$ Beau Busch, ${ }^{11}$ Rosemary Purcell ${ }^{1,2}$

To cite: Rice S, Olive L, Gouttebarge V, et al. Mental health screening: severity and cut-off point sensitivity of the Athlete Psychological Strain Questionnaire in male and female elite athletes. BMJ Open Sport \& Exercise Medicine 2020;6:e000712. doi:10.1136/ bmjsem-2019-000712

- Additional material is published online only. To view please visit the journal online (http://dx.doi.org/10.1136/ bmjsem-2019-000712).

Accepted 28 February 2020

Check for updates

(c) Author(s) (or their employer(s)) 2020. Re-use permitted under CC BY-NC. No commercial re-use. See rights and permissions. Published by BMJ.

For numbered affiliations see end of article.

Correspondence to A/Prof. Simon Rice simon.rice@orygen.org.au

\section{ABSTRACT}

Objectives To examine the sensitivity/specificity of the Athlete Psychological Strain Questionnaire (APSQ) in both male and female elite athletes, and also assess internal consistency and convergent/divergent validity, and determine discriminative validity relative to current injury status.

Methods Data were provided by 1093 elite athletes (males $n=1007$; females $n=84$ ). Scale validity and reliability values were benchmarked against validated measures of general psychological distress and well-being. ROC curve analysis determined a range of optimal severity cut-points.

Results Bias-corrected area under curve (AUC) values supported three APSQ cut-points for moderate $(A U C=0.901)$, high $(A U C=0.944)$ and very high $(A U C=0.951)$ categories. APSQ total score Cronbach coefficients exceeded those observed for the Kessler 10 (K-10). Gender xinjury status interactions were observed for the APSQ total score and K-10, whereby injured female athletes reported higher scores relative to males and noninjured female counterparts.

Conclusion By providing a range of cut-off scores identifying those scoring in the marginal and elevated ranges, the APSQ may better facilitate earlier identification for male and female elite athletes vulnerable to mental health symptoms and developing syndromes. Use of the APSQ may support sports medicine practitioners and allied health professionals to detect early mental ill health manifestations and facilitate timely management and ideally, remediation of symptoms.

There is growing interest into athlete mental health, as evidenced, in part, by the International Olympic Committee's (IOC) Consensus Statement on mental health in elite athletes. ${ }^{1}$ While self-report data provided by elite athletes indicates comparable prevalence rates of mental health symptoms to the general population (eg, anxiety/depression and sleep disorders), ${ }^{23}$ athletes are also exposed to various sports-related stressors not observed in the general population (such

\section{What are the new findings?}

The Athlete Psychological Strain Questionnaire provides cut-off scores to discriminate between 'moderate', 'high' and 'very high' levels of psychological distress in elite athletes.

- Female athletes suffering from an injury tend to experience greater psychological distress relative to uninjured female or male athletes.

- The Athlete Psychological Strain Questionnaire can be used to support sports medicine practitioners and allied professionals to detect early mental health symptoms in elite athletes.

as susceptibility to serious or chronic injury, performance impairments, popular and social media scrutiny and early or unplanned career termination). ${ }^{1}$ These stressors tend to be experienced during the peak age of onset for mental health disorders, ${ }^{4}$ which when combined, may increase athletes' susceptibility to psychological distress and mental health symptoms.

Despite this risk, there is a lack of wellvalidated athlete-specific screening tools that can assist with early detection of elite athletes experiencing psychological distress. Such screening tools may facilitate more timely intervention in the course of developing mental health symptoms. Rice et a $a \tilde{l}$ developed the multidimensional Athlete Psychological Strain Questionnaire (APSQ), which was modelled on the widely used and validated Kessler 10 (K-10). ${ }^{6}$ The APSQ is the recommended triage screening tool within the IOC's Sports Mental Health Assessment Tool, with a positive APSQ result leading to further symptom specific screening and assessment. ${ }^{7}$

The APSQ's psychometric evaluation included analyses demonstrating its reliability and validity among a large, representative sample of 1007 male elite athletes from three 
national Australian sports (Australian football, cricket and soccer), providing a single cut-off score. However, there is a need to provide support and coaching staff working in the elite sport environment with cut-off scores for less severe cases. Such earlier case identification may better facilitate timely referral and intervention, especially among athletes at elevated risk of impaired well-being, such as injured athletes. ${ }^{8}$ This short report extends earlier APSQ validation work by providing a range of less severe cut-off scores for mental health symptoms, while also including a female elite athlete sample. The aims of this study were to:

1. Explore the sensitivity/specificity of the APSQ in both male and female elite athletes with regard to their scores on the K-10.

2. Assess internal consistency and convergent/divergent validity of APSQ in male and female elite athletes.

3. Assess the discriminative validity of the APSQ to differentiate between injured and uninjured athletes in male and female athletes.

\section{METHOD}

\section{Participants}

Data were collected from a sample of 1091 elite athletes (males n=1007; females n=84) from three national Australian sports; Australian football (males only $\mathrm{n}=676 ; 84 \%$ response rate), cricket (males $n=126 ; 82 \%$ response rate, females $n=54 ; 53 \%$ response rate), soccer (males $n=203$; $78 \%$ response rate, females national squad $n=30 ; 100 \%$ response rate) N's do not total $100 \%$ due to missing data. All athletes were aged 18 years and over, identified as binary gender, and no exclusion criteria were applied (see table 1).

\section{Materials}

Respondents completed three validated self-report scales; the 10-item $\mathrm{APSQ}^{5}$ assessing three domains of self-regulation difficulties, performance concerns and externalised coping, in addition to providing a total score; the 10-item Kessler Psychological Distress Scale ${ }^{6}$ providing a measure of general psychological distress and the 14-item Warwick-Edinburgh Mental Well-Being Scale assessing mental well-being (WEMWBS). ${ }^{9}$

\section{Procedure}

All contracted athletes for the participating sports were invited to participate in an an anonymous online survey, conducted in group-based sessions. Clinician researchers were present to introduce and oversee the data collection, which occurred via tablets. Data collection occurred nationally in local club-based facilities and was coordinated by the participating sports and clubs.

\section{Statistical analyses}

The present study used secondary data analysis for the $\mathrm{n}=1007$ male athletes reported in Rice $e t a l^{5}$ and primary data analysis for the included $\mathrm{n}=84$ female athletes. Cronbach alpha coefficients and Pearson correlations were calculated to assess internal consistency and validity (convergent and divergent validity). A series of receiver operating characteristic (ROC) curve analyses were undertaken to identify the sensitivity and specificity of the APSQ total score in discriminating levels of severity on the K-10. Three analyses were conducted, with the ROC curve state variable either 'moderate' distress and above $(\mathrm{K}-10=16+)$, 'high' distress and above $(\mathrm{K}-10=22+)$ or 'very high' distress $(\mathrm{K}-10=30+)$. For each of these analyses, Youden's $(\mathrm{J})$ index was identified, which is a coefficient maximising the sensitivity and specificity of the respective cut-point. ${ }^{10}$ Previously, Rice et al ${ }^{5}$ reported a single preliminary cut-off score on the APSQ for identifying athletes who may be at risk of psychological distress and warrant mental health intervention. In order to facilitate even earlier detection for less severe cases, we sought to identify a series of APSQ cut-points. To guide interpretation, we used the accepted area under curve (AUC) values of $>0.90$ (very good), $>0.80$ (good) and $>0.70$ (fair). ${ }^{11}$ Between-group analyses examined differences by injury and gender status. Internal validation of AUC values and between-groups outcomes were undertaken with bootstrapping procedures using 10000 resamples. Analyses were conducted using SPSS V.26.0, with bias-corrected bootstrapping conducted in STATA V.15.0.

\section{RESULTS}

In addition to the sample of $\mathrm{n}=1007$ male elite athletes reported in Rice $e t a l,{ }^{5}$ this analysis incorporates data from 84 female elite athletes (of whom $\mathrm{n}=22$ were currently injured). Internal consistency values for the APSQ were all in the acceptable range (see table 1) for both male and female athletes, with the APSQ total score values exceeding those observed for the K-10.

\section{ROC curves and APSQ cut-offs}

A series of ROC curve analyses were undertaken to identify the sensitivity and specificity of the APSQ total score in discriminating levels of severity on the K-10. The diagnostic odds ratio (ie, positive likelihood ratio $\div$ negative likelihood ratio) of the three cut-off points indicted that the very high APSQ cut-off was better at discriminating cases than was the high or moderate cut-offs, both of which reported lower sensitivity and specificity, with bootstrap results validating the AUC values (see table 2).

\section{Convergent and divergent validity}

Pearson correlations were evaluated separately by gender (see table 3). Moderate-to-strong positive correlations were observed between the APSQ domains and the K-10, providing support for convergent validity. Conversely, moderate negative correlations were observed between the APSQ domains and the WEMWBS, supporting divergent validity. Bootstrapping indicated these correlations were internally valid (see online supplementary table 1 ). 
Table 1 Sample demographics and scale reliabilities

\begin{tabular}{|c|c|c|c|}
\hline \multirow[b]{2}{*}{ Variable } & & \multirow{2}{*}{$\begin{array}{l}\text { Males } \\
(n=1007)\end{array}$} & \multirow{2}{*}{$\begin{array}{l}\text { Females } \\
(n=84)\end{array}$} \\
\hline & & & \\
\hline Age & $\mathrm{M}(S D)$ & $23.7(4.1)$ & $23.8(5.2)$ \\
\hline \multicolumn{4}{|l|}{ Highest education completed } \\
\hline High school & n (\%) & 797 (79.3) & $39(46.4)$ \\
\hline Trade or technical education & n (\%) & $143(14.2)$ & $14(16.7)$ \\
\hline Completed a university degree & $\mathrm{n}(\%)$ & $65(6.5)$ & $29(34.5)$ \\
\hline Currently studying & $\mathrm{n}(\%)$ & $431(42.8)$ & $46(54.8)$ \\
\hline \multicolumn{4}{|l|}{ Marital status } \\
\hline Partnered/de-facto & $\mathrm{n}(\%)$ & $512(50.9)$ & $34(40.4)$ \\
\hline Single & $\mathrm{n}(\%)$ & $332(33.0)$ & $47(56.0)$ \\
\hline Married & n (\%) & $161(16.0)$ & $3(3.6)$ \\
\hline Separated & n (\%) & $2(0.2)$ & $0(0)$ \\
\hline Moved from home to play sport & n (\%) & $468(69.0)$ & $24(28.6)$ \\
\hline Another region within state & n (\%) & $134(13.3)$ & $5(6.0)$ \\
\hline Another state within Australia & n (\%) & $451(44.8)$ & $16(19.0)$ \\
\hline Another country & n (\%) & $65(6.5)$ & $3(3.6)$ \\
\hline \multicolumn{4}{|l|}{ Living situation } \\
\hline Renting & n (\%) & $464(46.1)$ & $21(25.0)$ \\
\hline My own home with mortgage & n (\%) & $277(27.5)$ & $17(20.2)$ \\
\hline Living with a host family & n (\%) & $56(5.6)$ & $2(2.4)$ \\
\hline My own home outright & n (\%) & $43(4.3)$ & $0(0)$ \\
\hline Family home & n (\%) & $152(15.1)$ & $38(45.2)$ \\
\hline Other & $\mathrm{n}(\%)$ & $14(1.4)$ & $6(7.1)$ \\
\hline \multicolumn{4}{|l|}{ Cultural background } \\
\hline Born in Australia & n (\%) & $916(91.1)$ & $75(89.3)$ \\
\hline Aboriginal or Torres Strait Islander & n (\%) & $69(6.9)$ & $5(6.8)$ \\
\hline Maori & n (\%) & $3(0.3)$ & $0(0)$ \\
\hline \multicolumn{4}{|l|}{ Time in current elite competition } \\
\hline$<1$ year & n (\%) & $108(10.7)$ & $13(15.5)$ \\
\hline $1-5$ years & n (\%) & $500(49.7)$ & $51(60.7)$ \\
\hline$>5$ years & n (\%) & $399(39.6)$ & $20(23.8)$ \\
\hline \multicolumn{4}{|l|}{ Current injury status } \\
\hline Uninjured & n (\%) & $717(71.3)$ & $61(72.6)$ \\
\hline $\begin{array}{l}\text { Currently injured/on adapted training } \\
\text { programme }\end{array}$ & n (\%) & $288(28.7)$ & $22(26.2)$ \\
\hline \multicolumn{4}{|l|}{ Scale reliability (cronbach coefficient) } \\
\hline APSQ self-regulation & $\alpha$ & 0.82 & 0.74 \\
\hline APSQ performance & $\alpha$ & 0.74 & 0.72 \\
\hline APSQ external coping & $\alpha$ & 0.68 & 0.80 \\
\hline APSQ total score & $\alpha$ & 0.87 & 0.84 \\
\hline $\mathrm{K}-10$ & $\alpha$ & 0.86 & 0.80 \\
\hline WEMWBS & $\alpha$ & 0.94 & 0.93 \\
\hline
\end{tabular}

APSQ, Athlete Psychological Strain Questionnaire; K-10, Kessler 10; WEMWBS, Warwick-Edinburgh Mental Well-Being Scale. 
Table 2 APSQ ROC curve and cut-point values (including bias-corrected AUC and 95\% Cls)

\begin{tabular}{|c|c|c|c|c|c|c|c|c|c|}
\hline APSQ cut-off & $\begin{array}{l}\text { APSQ positive } \\
\text { ( } \% \text { distribution) }\end{array}$ & Sensitivity, \% & Specificity, \% & Diagnostic OR & $\begin{array}{l}\text { AUC } \\
(95 \% \mathrm{Cl})\end{array}$ & $\begin{array}{l}\text { BC AUC } \\
(95 \% \mathrm{Cl})\end{array}$ & $\begin{array}{l}\text { Youden's (J) } \\
\text { Index }\end{array}$ & K-10 category & $\begin{array}{l}\text { K-10 positive } \\
\text { (\% distribution) }\end{array}$ \\
\hline $\begin{array}{l}\geq 15 \\
\text { 'Moderate' }\end{array}$ & $\begin{array}{l}\mathrm{n}=407 \text { (upper } \\
38.0 \text { ) }\end{array}$ & 84.8 & 79.3 & 21.31 & $\begin{array}{l}0.901^{* \star *} \\
(0.880 \text { to } \\
0.922)\end{array}$ & $\begin{array}{l}0.901^{\star \star \star} \\
(0.879- \\
0.920)\end{array}$ & 0.641 & 'Moderate' & $\begin{array}{l}\mathrm{n}=289 \\
\text { (upper 26.7) }\end{array}$ \\
\hline 'High' & $\begin{array}{l}\mathrm{n}=289 \\
\text { (upper 23.2) }\end{array}$ & 93.4 & 79.2 & 54.06 & $\begin{array}{l}0.944^{\star \star \star} \\
(0.926 \text { to } \\
0.962)\end{array}$ & $\begin{array}{l}0.944^{\star \star *} \\
(0.924 \text { to } \\
0.960)\end{array}$ & 0.726 & 'High' & $\begin{array}{l}\mathrm{n}=91 \\
\text { (upper 8.3) }\end{array}$ \\
\hline $\begin{array}{l}\geq 20 \\
\text { 'Very high' }\end{array}$ & $\begin{array}{l}\mathrm{n}=170 \\
\text { (upper 12.8) }\end{array}$ & 95.5 & 85.8 & 126.79 & 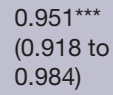 & $\begin{array}{l}0.951^{* * *} \\
(0.910 \text { to } \\
0.977)\end{array}$ & 0.813 & 'Very high' & $\begin{array}{l}\mathrm{n}=22 \\
\text { (upper 2.0) }\end{array}$ \\
\hline
\end{tabular}

BC $95 \% \mathrm{Cl}$ with 10000 bootstrap resamples.

${ }^{* * *} p<0.001$.

APSQ, Athlete Psychological Strain Questionnaire; AUC, area under curve; BC, Bias corrected; K-10, Kessler 10.

\section{Gender and current injury effects}

Between-groups analysis was conducted to examine gender (male, female) xinjury (injured, uninjured) effects (see table 4). Gender xinjury interactions were observed for the APSQ total score $F(1,1067)=17.82, \mathrm{p}<0.001, \eta^{2}=0.016$, (bootstrap $\mathrm{p}=0.001$ ), and also the $\mathrm{K}-10 F(1,1082)=13.38$, $\mathrm{p}<0.001, \eta^{2}=0.012$, (bootstrap $\mathrm{p}=0.001$ ). There was a significant main effect for gender on the WEMWBS $F(1$, 1064) $=18.31, \mathrm{p}<0.001, \eta^{2}=0.017$, (bootstrap $\left.\mathrm{p}<0.001\right)$ and a trend-level effect for injury $F(1,1064)=3.86, \mathrm{p}=0.050$, $\eta^{2}=0.014$, (bootstrap $\mathrm{p}<0.001$ ) but not a significant interaction $(p=0.197$; bootstrap $p=0.225)$. For the APSQ and K-10 gender xinjury interactions, females experiencing current injury tended to report higher scores, relative to uninjured females or males.

\section{DISCUSSION}

The need for validated athlete-specific questionnaires that are acceptable and appropriate for measuring mental health symptoms in the athlete environment is increasingly manifest. ${ }^{12}$ The APSQ was designed specifically with the athletic context in mind, relative to behaviours that may indicate underlying distress in sports settings. The results of the present analyses not only support the use of the APSQ among both male and female elite athletes, but provide a validated range of cut-off points, reflecting moderate, high and very high scores. If measured repeatedly at regular intervals, the moderate cut-off point in particular may facilitate earlier case identification and subsequent intervention for athletes vulnerable to mental health symptoms and developing syndromes. The ROC curve AUC values for the three cut-off scores (all $>0.90$ ) indicate that the APSQ is 'very good' at correctly discriminating moderate, high and very high distress in both male and female athletes, benchmarked against the K-10. Professional sports organisations may consider use of the APSQ as a periodic screening tool, which could be implemented at key stages throughout the training or competitive season, or coinciding with athlete injury or career transition. Future research is needed to explore the prognostic value of the APSQ including associations with clinician diagnosed mental health disorders, in addition to exploring correlations between APSQ scores and current athletic performance or achievement.

\section{Gender and injury effects}

The results also indicated that currently injured female athletes reported the highest APSQ scores, as evidenced by the gender xinjury interactions. While we acknowledge that the sample included a relatively small number of injured female athletes $(n=22)$, this result may in part reflect the less resourced supports and well-being services available to female sports, given their relatively earlier stages of professionalisation. ${ }^{13}$ In addition, the present sample of female athletes was insufficient to conduct confirmatory factor analysis, where samples of $>300$ cases are recommended. Nonetheless, scale reliability values indicated satisfactory internal consistency of the APSQ

Table 3 APSQ, K-10 and WEMWBS correlations by gender

\begin{tabular}{|c|c|c|c|c|c|c|}
\hline & $\begin{array}{l}\text { APSQ self- } \\
\text { regulation }\end{array}$ & APSQ performance & $\begin{array}{l}\text { APSQ external } \\
\text { coping }\end{array}$ & APSQ total & $\mathrm{K}-10$ total & WEMWBS \\
\hline APSQ self-regulation & - & $0.506^{\star * *}$ & $0.528^{\star \star \star}$ & $0.821^{* \star *}$ & $0.716^{\star \star \star}$ & $-0.463^{\star * *}$ \\
\hline APSQ performance & $0.635^{\star \star \star}$ & - & $0.563^{\star \star \star}$ & $0.883^{\star * *}$ & $0.501^{\star \star \star}$ & $-0.346^{\star \star \star}$ \\
\hline APSQ external coping & $0.580^{\star * *}$ & $0.499^{* * *}$ & - & $0.757^{* * *}$ & $0.355^{\star}$ & $-0.226^{\star}$ \\
\hline APSQ total & $0.891^{\star \star \star}$ & $0.893^{\star \star \star}$ & $0.719^{\star \star \star}$ & - & $0.658^{\star \star \star}$ & $-0.437^{\star \star \star}$ \\
\hline $\mathrm{K}-10$ total & $0.768^{\star \star \star}$ & $0.643^{\star \star *}$ & $0.564^{\star \star *}$ & $0.787^{\star \star *}$ & - & $-0.574^{\star \star *}$ \\
\hline WEMWBS & $-0.495^{\star \star \star}$ & $-0.440^{\star \star \star}$ & $-0.363^{\star \star \star}$ & $-0.520^{\star \star \star}$ & $-0.481^{\star \star \star}$ & - \\
\hline
\end{tabular}

Female coefficients bolded above the diagonal.

${ }^{*} \mathrm{P}<0.05,{ }^{* *} \mathrm{P}<0.01,{ }^{* \star *} \mathrm{P}<0.001$

APSQ, Athlete Psychological Strain Questionnaire; K-10, Kessler 10; WEMWBS, Warwick-Edinburgh Mental Well-Being Scale. 
Table 4 Means, SDS and 95\% Cls and bias-corrected 95\% Cls by gender and injury status

\begin{tabular}{|c|c|c|c|c|c|c|}
\hline & \multicolumn{3}{|l|}{ Injured } & \multicolumn{3}{|l|}{ Uninjured } \\
\hline & M (SD) & $95 \% \mathrm{Cl}$ & $\mathrm{BC} 95 \% \mathrm{Cl}$ & M (SD) & $95 \% \mathrm{Cl}$ & $\mathrm{BC} 95 \% \mathrm{Cl}$ \\
\hline \multicolumn{7}{|l|}{ Male } \\
\hline APSQ self-regulation & $5.97(2.76)$ & (5.64 to 6.28$)$ & (5.65 to 6.29 ) & $5.68(2.34)$ & (5.50 to 5.84$)$ & (5.51 to 5.88$)$ \\
\hline APSQ performance & $6.81(3.00)$ & (6.46 to 7.16$)$ & (6.47 to 7.17 ) & $6.26(2.63)$ & (6.06 to 6.45$)$ & (6.06 to 6.45$)$ \\
\hline APSQ external coping & $2.58(1.29)$ & (2.42 to 2.72 ) & (2.43 to 2.50$)$ & $2.46(1.05)$ & (2.39 to 2.54 ) & (2.39 to 2.50 ) \\
\hline APSQ total score & $15.36(6.10)$ & (14.64 to 16.10$)$ & (14.67 to 16.10$)$ & $14.40(5.18)$ & (14.02 to 14.79$)$ & (14.04 to 14.79$)$ \\
\hline $\mathrm{K}-10$ & $14.08(4.74)$ & (13.53 to 14.63 ) & (13.55 to 14.64$)$ & $14.19(4.82)$ & (13.88 to 14.55$)$ & (13.84 to 14.55$)$ \\
\hline WEMWBS & $50.84(9.09)$ & (49.77 to 51.90 ) & (49.72 to 51.89 ) & $51.61(8.83)$ & (50.96 to 52.27 ) & (50.97 to 52.27 ) \\
\hline \multicolumn{7}{|l|}{ Female } \\
\hline APSQ self-regulation & $9.14(2.44)$ & (8.06 to 10.21 ) & (8.13 to 10.13 ) & $6.04(2.32)$ & (5.45 to 6.65$)$ & (5.49 to 6.65 ) \\
\hline APSQ performance & $9.50(4.26)$ & (7.61 to 11.39 ) & (7.80 to 11.37 ) & $6.74(2.73)$ & (6.04 to 7.44$)$ & (6.08 to 7.45$)$ \\
\hline APSQ external coping & $3.36(2.38)$ & (2.31 to 4.42 ) & (2.46 to 4.41$)$ & $2.30(0.74)$ & (2.11 to 2.48 ) & (2.12 to 2.48 ) \\
\hline APSQ total score & $22.00(7.99)$ & (18.46 to 25.54$)$ & (18.91 to 25.52 ) & $15.08(4.41)$ & (13.95 to 16.21$)$ & (14.00 to 16.23 ) \\
\hline $\mathrm{K}-10$ & $19.36(5.46)$ & (16.94 to 21.79 ) & (17.17 to 21.74 ) & $14.97(4.06)$ & (13.93 to 16.01$)$ & (14.02 to 16.02$)$ \\
\hline WEMWBS & $44.41(9.13)$ & (40.36 to 48.46 ) & (40.41 to 48.24 ) & 48.17 (8.80) & (45.89 to 48.46 ) & (45.95 to 50.39 ) \\
\hline
\end{tabular}

BC $95 \% \mathrm{Cl}=$ bias corrected $95 \% \mathrm{Cl}$ with 10000 bootstrap resamples.

APSQ, Athlete Psychological Strain Questionnaire; K-10, Kessler 10; WEMWBS, Warwick-Edinburgh Mental Well-Being Scale.

among female athletes, with the Cronbach coefficient for the APSQ total score exceeding the value observed for the K-10 (for both females and males). Additional research using the APSQ in larger, representative female athlete samples is required, as is research exploring gender differences for the APSQ.

\section{CONCLUSION}

Through the use of a range of cut-off scores, the APSQ may assist sports medicine practitioners and allied health professionals to better detect the early manifestations of mental health symptoms experienced by both male and female elite athletes. This in turn can facilitate timely management and ideally, remediation of symptoms.

\section{Author affiliations}

${ }^{1}$ Orygen, Parkville, Victoria, Australia

${ }^{2}$ Centre for Youth Mental Health, The University of Melbourne, Melbourne, Victoria, Australia

${ }^{3}$ School of Psychology, Deakin University, Burwood, Victoria, Australia

${ }^{4}$ Amsterdam UMC, Univ of Amsterdam, Department of Orthopaedic Surgery, Amsterdam Movement Sciences, Meibergdreef 9, Amsterdam, the Netherlands ${ }^{5}$ Amsterdam Collaboration on Health \& Safety in Sports (ACHSS), Amsterdam UMC IOC Research Center of Excellence, Amsterdam, Netherlands

${ }^{6}$ Division of Exercise Science and Sports Medicine, University of Cape Town, Cape Town, South Africa

${ }^{7}$ Institute for Health and Sport, Victoria University, Melbourne, Victoria, Australia

${ }^{8}$ Australian Football League, Melbourne, Victoria, Australia

${ }^{9}$ Cricket Australia, Melbourne, Victoria, Australia

${ }^{10}$ AFL Players' Association, Melbourne, Victoria, Australia

${ }^{11}$ Professional Footballers Australia, Melbourne, Victoria, Australia

\section{Twitter Vincent Gouttebarge @VGouttebarge}

Acknowledgements The authors thank the participating professional codes and associations for support with project administration and data collection.

Contributors Study conception and management of ethics approval process was undertaken by RP, AGP, SR. Planning and support for data collection and refining measures was undertaken by RP, AGP, SR, PC, PH, ML, AK and BS. Interpretation of data was led by RP, AGP and SR with support from LO, VG, PC, PH, ML, AK, BS and $\mathrm{BB}$. Data analysis was undertaken by SR. Writing of the manuscript was led by SR with all authors contributing to multiple drafts of the manuscript. All authors approved the final submitted version.

Funding Simon Rice was supported by a Career Development Fellowship from the NHMRC (APP1158881). This study was, in part, made possible from funding from several sporting bodies, all of whom requested anonymity.

Competing interests None declared.

Patient consent for publication Not required.

Ethics approval Ethical approval for the study was granted by The University of Melbourne Human Research Ethics Committee (ID: 1442705).

Provenance and peer review Not commissioned; externally peer reviewed.

Data availability statement № data are available.

Open access This is an open access article distributed in accordance with the Creative Commons Attribution Non Commercial (CC BY-NC 4.0) license, which permits others to distribute, remix, adapt, build upon this work non-commercially, and license their derivative works on different terms, provided the original work is properly cited, appropriate credit is given, any changes made indicated, and the use is non-commercial. See: http://creativecommons.org/licenses/by-nc/4.0/.

\section{ORCID iDs}

Simon Rice http://orcid.org/0000-0003-4045-8553

Vincent Gouttebarge http://orcid.org/0000-0002-0126-4177

\section{REFERENCES}

1 Reardon CL, Hainline B, Aron CM, et al. Mental health in elite athletes: international Olympic Committee consensus statement (2019). Br J Sports Med 2019;53:667-99.

2 Gouttebarge V, Castaldelli-Maia JM, Gorczynski P, et al. Occurrence of mental health symptoms and disorders in current and former elite athletes: a systematic review and meta-analysis. Br J Sports Med 2019;53:700-6

3 Rice SM, Gwyther K, Santesteban-Echarri O, et al. Determinants of anxiety in elite athletes: a systematic review and meta-analysis. $\mathrm{Br} \mathrm{J}$ Sports Med 2019;53:722-30.

4 Kessler RC, Wang PS. The descriptive epidemiology of commonly occurring mental disorders in the United States. Annu Rev Public Health 2008;29:115-29.

5 Rice SM, Parker AG, Mawren D, et al. Preliminary psychometric validation of a brief screening tool for athlete mental health among 
male elite athletes: the athlete psychological strain questionnaire. Int $J$ Sport Exerc Psychol 2019;6:1-16.

6 Kessler RC, Andrews G, Colpe LJ, et al. Short screening scales to monitor population prevalences and trends in non-specific psychological distress. Psychol Med 2002;32:959-76.

7 Gouttebarge V. Overview of the IOC consensus statement on mental health in elite sports. 18th Biennial Congress of the South African Sports Medicine Association (SASMA). Cape Town, South Africa, 2019.

8 Abbott W, Brownlee TE, Harper LD, et al. A season long investigation into the effects of injury, match selection and training load on mental wellbeing in professional under 23 soccer players: a team case study. Eur J Sport Sci 2019;19:1250-6.

9 Stewart-Brown S, Tennant A, Tennant R, et al. Internal construct validity of the Warwick-Edinburgh mental well-being scale
(WEMWBS): a Rasch analysis using data from the Scottish health education population survey. Health Qual Life Outcomes 2009;7:15.

10 Perkins NJ, Schisterman EF. The inconsistency of "optimal" cutpoints obtained using two criteria based on the receiver operating characteristic curve. Am J Epidemiol 2006;163:670-5.

11 Ekelund S. Roc Curves-What are they and how are they used? Point Care 2012;11:16-21.

12 Donohue B, Galante M, Hussey J, et al. Empirical development of a screening method to assist mental health referrals in collegiate athletes. J Clin Sport Psychol 2019:1-28.

13 Hickey C, Harrison L, Ollis D, et al. The professionalisation of Australian women's cricket: New times and new opportunities. Australia: Deakin University, 2016. 